\title{
Evolving concepts of chronic traumatic encephalopathy as a neuropathological entity
}

Helen Ling, MRCP PhD*1,2,3, James W Neal, DPhil, FRCPath ${ }^{4}$, Tamas Revesz MD, FRCPath $^{1,2,3}$

\section{Affiliations:}

1. Queen Square Brain Bank for Neurological Disorders, UCL Institute of Neurology, University College London, London, UK

2. Reta Lila Weston Institute for Neurological Studies, UCL Institute of Neurology, London, UK

3. Department of Molecular Neuroscience, UCL Institute of Neurology, University College London, London, UK

4. Department of Cellular Pathology, Cardiff University, Wales, UK

\section{Corresponding author:}

Dr Helen Ling, Email: h.ling@ucl.ac.uk; Address: Reta Lila Weston Institute of Neurological Studies, 1 Wakefield Street, UCL Institute of Neurology, London WC1N 1PJ, United Kingdom; Tel.: +44 2007679 4025; Fax: +44 2034484286

Keywords: chronic traumatic encephalopathy, repetitive head impact, traumatic brain injury, concussion, tauopathy

Word count: 3048

Table: 1

Figure: 2

Reference: 76 


\begin{abstract}
:
Chronic traumatic encephalopathy (CTE) is a long-term neurodegenerative consequence of repetitive head impacts which can only be definitively diagnosed in post-mortem. Recently, the consensus neuropathological criteria for the diagnosis of CTE was published requiring the presence of the accumulation of abnormal tau in neurons and astroglia distributed around small blood vessels at the depths of cortical sulci in an irregular pattern as the mandatory features. The clinical diagnosis and antemortem prediction of CTE pathology remain challenging if not impossible due to the common co-existing underlying neurodegenerative pathologies and the lack of specific clinical pointers and reliable biomarkers. This review summarises the historical evolution of CTE as a neuropathological entity and highlights the latest advances and future directions of research studies on the topic of CTE.
\end{abstract}


Introduction

In 1928, Martland described the clinical features of 'punch drunk' in boxers[1], a condition later known as 'dementia pugilistica'[2]. 'Chronic traumatic encephalopathy', first coined by Critchley[3], then became the preferred term which has been widely used in the recent surge in scientific and public interest in this neurodegenerative consequence linked with past exposure to subconcussive or concussive repetitive head impacts (RHI).

The seminal paper by Corsellis and colleagues describing neuropathological features of the brains of 15 retired boxers delineated CTE as a distinct entity which can only be definitively diagnosed post-mortem[4]. CTE has not only been reported in athletes who had participated in various contact sports (boxing, American football, rugby, Association football/soccer, baseball, wrestling, ice hockey)[5], but also in military personnel exposed to explosive blast[6] and individuals exposed to RHI including physical abuse[7], head banging[8, 9], intractable epilepsy[8], and dwarf-throwing[10].

\section{Historical perspectives}

The neuropathological concept of CTE is relatively new. Corsellis and colleagues identified generalized cerebral atrophy, enlargement of the ventricles, widespread neocortical neurofibrillary tangles (NFTs), neuropil threads (NTs) in elderly retired boxers[4]. Similar neuropathological features were also described in other case series of retired boxers[11-13]. Subsequent re-examination of the Corsellis series of boxers identified the presence of diffuse amyloid- $\beta(\mathrm{A} \beta)$ plaques as a characteristic feature of $\mathrm{CTE}[4,11,14]$. Cavum septi pellucidi (CSP) and septal fenestration were found in all 11 professional boxers in Corsellis's original series, except in one case in whom the CSP was not observed as 'the septum was nevertheless fenestrated to destruction' [4]. The prevalence of these septal abnormalities was found in up to $6 \%$ of non-boxers in the same autopsy series, supporting of their association with RHI exposure[4]. In 1999, Geddes and colleagues reported the early histological changes of five men who had died in their 20's with a history of RHI exposure[8]. The study confirmed predominantly neocortical NFT formation, but the lack of amyloid $\beta$-protein (A $\beta)$ deposits in these young individuals. Importantly, the predominant deposition of NFTs and neuropil threads around blood vessels in the cortices with predilection to the depths of the sulci was highlighted as a distinctive feature of CTE[8] differentiating CTE from the NFT pathology 
seen in Alzheimer's disease (AD). This corroborated the same significant observation previously reported by Hof and colleagues[9]. The transactive response (TAR) DNA binding protein with a molecular weight of 43-kDa (TDP-43) is the major ubiquitinated protein in frontotemporal lobar degeneration with TDP-positive inclusions (FTLD-TDP) and in amyotrophic lateral sclerosis(ALS) or motor neuron disease (MND)[15, 16]. In 2010, King and colleagues identified TDP-43 inclusions in all of the three screened cases with CTE, highlighting TDP-43 as a common concurrent feature in CTE[17]. The similarity in the distribution of TDP-43 inclusions between CTE and FTLD-TDP led the authors to propose a potential shared pathogenic mechanism between the two conditions.

\section{CTE and AD}

Like the disease-associated tau in $\mathrm{AD}$, the abnormally hyperphosphorylated tau aggregates in CTE are composed of both 4-repeat and 3-repeat tau isoforms[18]. Histologically, the preferential accumulation of tau aggregates in superficial cortical layers differentiates CTE from AD, in which NFTs are predominant in the deeper cortical laminae[19]. Occasionally, confluent tau pathology in severe AD may preclude the definitive delineation of concurrent CTE pathology. The accumulation of hyperphosphorylated tau in CTE following traumatic brain injury is believed to be the result of mechanical microtubule breakage at the sites of axonal injury, leading to tau liberation and its hyperphosphorylation[20]. Nevertheless, abnormal tau accumulation is not an immediate consequence as tau pathology was not observed in autopsy studies of patients dying in the acute phase, up to four weeks' survival, following a single event of traumatic brain injury[21]. However, this was observed in some patients dying one year or more after a single event of traumatic brain injury[22] and consistently in cases of CTE[23]. Furthermore, recent immunohistochemical and biochemical studies demonstrated distinct differences in the constellation of tau epitopes between the filamentous tau inclusions in CTE and those in $\mathrm{AD}$ [24], which may shed light in the pathogenesis of tau in CTE.

Amyloid- $\beta$ deposition, another pathological hallmark of $\mathrm{AD}$, is also a common feature in older individuals with CTE[23]. A recent study showed that diffuse plaques were present in $52 \%$ and neuritic plaques in $36 \%$ of pathologically confirmed CTE cases, and that A $\beta$ deposition was associated with older age at symptom onset and at death, possession of the 
APOE4 allele and more severe tau burden, suggesting its potential modulating effect in the pathological progression of CTE[25].

Current evidence supports the notion that head injury increases the risk of $\mathrm{AD}$, although the definition of head injury varies between studies ranging from a single concussive episode with loss of consciousness or various severity and frequency of shead impacts. The association of a history of head injury and AD-like dementia is supported by epidemiological studies[26, 27], however the link between head injury and the development of AD pathology will require post-mortem confirmation in future studies. Other studies have demonstrated excessive $A \beta$ genesis following traumatic brain injury[28]. Increased accumulation of $A \beta$ precursor protein (APP) in injured axons are observed acutely hours after traumatic brain injury[29, 30]. Components of both the $\beta$ and $\gamma$ cleavage of APP such as BACE ( $\beta$-site-APPcleaving enzyme) and presenilin-1 have also been shown to co-localise with APP in injured neurons[31]. Amyloid $\beta$-diffuse plaques, similar to those observed in early AD, are observed more frequently in brain tissue of individuals, including young adults, following acute traumatic brain injury, than in age-matched subjects[32-34]. The normal order in amyloid cycling is gradually restored in the months following brain trauma with clearance of acute A $\beta$-plaques[35]. Nevertheless, in a proportion of susceptible individuals, the A $\beta$-plaque formation process may persist beyond the acute phase of traumatic brain injury, and factors such as age, APOE4 carrier status, force and interval of RHI, and other hitherto unknown genetic and environmental factors, are likely to come into play. This notion is supported by autopsy studies demonstrating $A \beta$-plaques in brain tissue of individuals who survived one year or more after a single event of traumatic brain injury in significantly higher density and in more widespread distribution than in age-matched uninjured control brains[22]. More research effort focusing on amyloid pathologies in CTE is required[36].

Recent neuropathological diagnostic criteria

In 2013, the delineation of the neuropathological characteristics of CTE was consolidated by McKee and colleagues' landmark clinico-pathological series of 68 cases, which remains the largest case series to date[23]. The preliminary diagnostic criteria and a 4-tiered staging scheme, with increasing severity and distribution of tau accumulation correlating with progression of clinical symptoms, were proposed. This work led to the consensus National 
Institute of Neurological Disorders and Stroke (NINDS) neuropathological criteria for the diagnosis of CTE in 2016[19]. The criteria require the presence of the pathognomonic lesions, defined as accumulation of abnormal tau in neurons and astroglia distributed around small blood vessels at the depths of cortical sulci in an irregular pattern[19](Figure 1). Supportive microscopic features include tau depositions in the superficial cortical layers (layers II-III), NFTs found preferentially in the hippocampal CA2 subregion, prominent proximal dendritic swellings in CA4, neuronal and astrocytic tau aggregates in subcortical nuclei, thorny astrocytes in the subpial and periventricular regions, and large tau-positive grain-like and dot-like structures in the cell processes that are most dense in the perivascular areas. Other non-tau related supportive features are dilatation of the third ventricle, CSP and septal fenestration, mammillary body atrophy and TDP-43 pathology (Table 1).

Aging-related tau astrogliopathy

Astroglial tau aggregates are commonly observed in the aging brain without association with any co-existing neuropathological disorders or clinical symptoms such as dementia, and are now referred as aging-related tau astrogliopathy (ARTAG)[37]. The frequency of ARTAG increases with age and is rare in individuals below the age of 60[37]. Wharton and colleagues reported thorn-shaped astrocytes (TSAs), a characteristic feature of ARTAG, in $40 \%$ of aged brains in a large population-based cohort (mean age: 85.9 years)[38], whereas Liu and colleagues identified ARTAG in $33.8 \%$ of aged brains with either Lewy body disorders, AD and healthy controls (mean age: 78.8 years)[39].

Some of the ARTAG features previously described in the 2013 series by McKee and colleagues[23], including patchy TSAs in subcortical white matter, mediobasal regions, amygdala and hippocampus, are now considered by the NINDS consensus criteria as nonspecific and non-diagnostic for CTE[19]. The reverse is likely to be true that, prior to the publication of the systematic evaluation of ARTAG in 2016[37], CTE-tau pathology observed in aged brains might have been considered as non-specific age-related astrocytic changes which, in the past, had been poorly characterized and commonly disregarded in neuropathological assessments.

In both CTE[19] and ARTAG[37], there is a predilection of TSAs in the perivascular, subpial and periventricular regions. Nevertheless, the predilection of tau aggregates at the depths of 
the sulci is specific for CTE[19, 37]. The shared characteristic of perivascular accentuation of astroglial tau pathology suggests a common down-stream mechanism of impaired blood-brain barrier; one that is caused by age-related processes in ARTAG, and the other caused by chronic neuroinflammation following RHI in CTE[40-43]. Whether CTE represents an advanced form of ARTAG pathology with additional neuronal tau aggregates remains to be established.

\section{Neuroinflammation}

Chronic neuroinflammation is increasingly recognised as a consequence of RHI (Figure 2). Many studies have demonstrated the occurrence of acute neuroinflammation following head impact $[6,44,45]$. Mouse models exposed to RHI have shown astroglial and microglial activation preceding the formation of tau pathology[46-48]. These findings may be of significant relevance for the selection of biomarkers related to neuroinflammation to identify the early changes of CTE and potential therapeutic targets in at risk population[40, 42, 43, 49].

In a quantitative study using post-mortem brain tissue of American football athletes from the Boston cohort, Cherry and colleagues reported an association between an increased number of CD68 immunoreactive microglia in the dorsolateral frontal cortex and the duration of RHI exposure as well as the development and severity of CTE[40]. A clinical diagnosis of dementia was also significantly predicted by CD68 cell density independent of age[40]. The findings of this study support the notion that RHI is associated with chronic activation of microglia which in turn contributes to the manifestation of dementia and the development of CTE-tau pathology. Interestingly, this study also reported an elevated CD68 cell density in athletes exposed to RHI but did not have CTE-tau pathology[40]. These individuals were younger and had shorter duration of RHI exposure when compared to the CTE group and possibly represent a prodromal subgroup [40]. 
CTE and neurodegenerative disorders

CTE is increasingly recognised as a mixed proteinopathy with accumulation of mixed 3repeat and 4-repeat tau within neurons, which is frequently accompanied by TDP-43 and A $\beta$ depositions. In aged brains with CTE, the findings of other co-morbid neurodegenerative pathologies are common and were identified in almost half of all CTE cases in the Boston cohort $[23,50]$. Of the 103 pathologically confirmed CTE cases, co-existing AD, MND, Lewy body disease and FTLD were found in $15 \%, 13 \%, 12 \%$ and $6 \%$, respectively[23, 50]. To establish the prevalence of CTE pathology in elderly individuals, our group screened 268 consecutive cases of various NDDs and healthy controls in the Queen Square Brain Bank for Neurological Disorders[51] using the preliminary 2013 McKee diagnostic criteria. The study identified early histological evidence of CTE in $11.9 \%$ of NDDs and $12.8 \%$ of controls over the age of 60 [51]. Of the 32 CTE-positive cases, $93.8 \%$ had a history of TBI established by retrospective review of medical records and telephone interview. Interestingly, the highest prevalence of CTE was $24 \%$ identified in cases with the primary neuropathological diagnosis of progressive supranuclear palsy (PSP), a condition that leads to frequent falls and RHI as a result even at the early disease stage[51, 52]. The high prevalence of co-morbid neurodegenerative diseases (NDDs) in these studies suggest that either CTE and NDDs share the common risk factor of RHI or CTE-tau accumulation predisposes the aging brain to the deposition of other disease-associated proteins. Likewise, the association of RHI in athletes and MND has been proposed[53-55]. There is a higher incidence of ALS in Association footballers (soccer players) in Italian epidemiological studies[53, 54]. McKee and colleagues reported a 29-yar old semi-professional footballer who was clinically diagnosed with ALS and post-mortem examination not only confirmed TDP-43 proteinopathy affecting the brain and spinal cord consistent with the pathological diagnosis of MND, but also demonstrated early CTE histological changes[5]. American football players who played professionally for more than five seasons also showed a four-fold increased risk of dying from ALS.

Clinico-pathological correlations

The delineation of the clinical features of CTE can be challenging due to co-existing NDDs[52] and, in some cases, persistent post-concussive symptoms[41]. The clinical presentation is generally characterized by involvement of four domains: mood, behaviour, 
cognitive and motor impairments[56, 57]. Motor impairment, including dysarthria, dysphagia, parkinsonism and cerebellar ataxia, was frequently described in retired boxers[58]. Clinical criteria have been proposed for the diagnosis of CTE[56, 59, 60], but validation using a large clinico-pathological series with longitudinal clinical follow-up is required.

Stern and colleagues reviewed 36 cases with pure CTE pathology and found that individuals with younger age of onset (mean age: 35 years) were more likely to present with initial behavioural and mood changes and later progress to cognitive impairment, whereas those with older age of onset (mean age: 59 years) tended to present with cognitive impairment such as difficulties with episodic memory and executive function[61]. With lack of reliable biomarkers, the clinical diagnosis is challenging as these clinical phenotypes mimic the clinical features of frontotemporal dementia and AD. In addition, a small proportion of pathologically confirmed CTE cases were clinically asymptomatic and they are associated with mild focal rather than advanced CTE pathology. In the Boston series, 3 of the 36 pure CTE cases (8\%)[61] and $11 \%$ of all pathologically confirmed CTE cases were clinically asymptomatic[23].

\section{Risk factors}

The duration of exposure to contact sports is significantly associated with more severe CTEtau pathology, suggesting that the chronic and cumulative nature of RHI is the most important risk factor of CTE[23, 62]. This notion is supported by the absence of a concussion history (i.e. head impacts associated with significant neurological symptoms) in $16 \%$ of published CTE cases[62]. Recently, our group reported the pathological findings of CTE fulfilling the latest NINDS diagnostic criteria in 4 of 6 retired Association footballers, whose brains were examined[63]. Association football (soccer) is unique as players are exposed to substantial amount of various types of RHI throughout their career, including heading of the ball and head collisions, which are rarely associated with overt neurological symptoms, unlike in boxing or American football. The retired footballers included in our series had long career averaging of 26 years and all were skilled headers of the ball. Most importantly, concussion associated with loss of consciousness was reported in 5 of 6 ex-footballers 
limiting to only one episode each. This suggests that subconcussive RHI exposure is the main potential link to the development of CTE in these cases.

Not all individuals develop CTE pathology following exposure to RHI. In a Mayo Clinic Brain Bank Study, Bieniek and colleagues found a prevalence of criteria-defined CTE pathology[19] in 21 of 66 (32\%) former athletes in their archival cohort of 1721 men after excluding cases with primary tauopathies including PSP, CBD, Pick's disease and FTLD17MAPT[64]. Dose-response relationship including threshold of impact force, frequency, intervals and their associated risk of CTE remain to be established[65]. Genetic susceptibility, such as APOE allele[25], MAPT H1 haplotype and TMEM106B[64], may modify CTE risk, but their significance will need to be validated future studies. Furthermore, age of RHI exposure[66-68], biomechanics of the impact force, cognitive reserve[69], and lifestyle choices including alcohol and substance abuse, chronic use of analgesics and performanceenhancing drugs[70] have all been hypothesized to influence the susceptibility to CTE development and modulate the clinical manifestation.

Mouse and computational models

The findings of mouse models of CTE have been inconsistent with only half of the studies demonstrating tau aggregates following exposure to RHI[71]. When interpreting the results of mouse models, fundamental differences between human and rodent brains should be taken into consideration. For instance, increased levels of 4-repeat tau are found in rodent cortex, which promotes binding to microtubules leaving less 4-repeat tau available for hyperphosphorylation and NFT formation[72]. Human and mouse tau differ significantly in the length of amino acid sequence at the amino terminus and this prevents tau-tau interactions and inhibits fast axonal transport, both of which hinder the potential for the formation of tau inclusions in mice[71]. In a recent mouse study, lightly anaesthetized unrestrained mice exposed to 30 RHIs over six weeks were sacrificed 53 days after the final head impacts[48]. Neuropathological examination of mouse brains approximately two months after the last head impact showed CTE-like features with neuroinflammation inferred by the presence of astrogliosis and microgliosis, depositions of hyperphosphorylated tau, A $\beta$, and TDP-43[48]. The findings of this study support the causal relationship between RHI and CTE. 
A computational model of brain injury biomechanics was developed to improve the understanding between RHI and the pattern of CTE pathology[73]. The study showed brain tissue deformation induced by head impact loading was greatest in sulcal locations, where the CTE-tau pathology predominated. Diffusion tensor imaging, a neuroimaging technique widely used to estimate the long-term effects of RHI, showed converging imaging abnormalities within the cortical sulcal regions in RHI patients with decrease in fractional anisotrophy when compared to controls[73]

Future directions

The aetiology of CTE is a topic of significant public health interest. There is a pressing need to identify the key risk factors to implement protective strategies for athletes and military personnel. To identify potential risk factors for CTE will require well designed and largescaled longitudinal prospective studies with sequential collection of objective measurement of head impact exposure, clinical data, genetic analysis, neurocognitive testing, neuroimaging and fluid biomarkers. Studies involving fluid biomarkers are essential to identify the early and, potentially reversible, stages of CTE in populations exposed to RHI before any structural changes become irreversible. Promising biomarkers in at risk populations include CSF levels of $\mathrm{A} \beta$, tau and neurofilament light (NF-L), diffusion tensor imaging[74], and PET imaging using FDDNP (2-(1-[6-[(2-[F-18]fluoroethyl)(methyl)amino]-2naphthyl]ethylidene)malononitrile)[75], a ligand that binds to both NFTs and A $\beta$ aggregates in the brain. These data will finally require both validation and correlation with the newly established neuropathological criteria of CTE obtained by post-mortem examination to provide answers to some of the questions raised in this review. 


\section{Table 1:}

Preliminary NINDS criteria for the pathologic diagnosis of CTE [19].

\section{Mandatory features:}

1. Tau inclusions in neurons, astrocytes, cell processes around small vessels in an irregular pattern at the depths of the cortical sulci

\section{Supportive neuropathological features of CTE:}

Tau pathologies:

1. Pretangles and NFTs preferentially accumulating in the superficial cortical layers

2. NFTs or ghost tangles preferentially observed in hippocampal CA2 subregion and prominent proximal dendritic swellings in CA4 subregion

3. Neuronal and astrocytic lesions in subcortical nuclei, including the mammillary bodies, hypothalamic nuclei, amygdala, nucleus accumbens, thalamus, midbrain tegmentum, nucleus basalis of Meynert, raphe nuclei, substantia nigra and locus coeruleus

4. Thorn-shaped astrocytes in the glial limitans in the subpial and periventricular regions

5. Large grain-like and dot-like structures in the cell processes in addition to threadlike neurites

Non-tau pathologies:

1. Disproportionate dilatation of the third ventricle, septal abnormalities, mammillary body atrophy, and contusions or other signs of previous traumatic injury

2. TDP-43 immunoreactive neuronal cytoplasmic inclusions and dot-like structures in the hippocampus, anteromedial temporal cortex and amygdala 



\section{Figure 1:}

The characteristic histological features of CTE. Tau immunohistochemistry demonstrates neuronal lesions preferentially affecting the superficial cortical layers (a), and the pathognomonic lesions consisting of patchy tau aggregates in neurons, astrocytes and cell processes in the perivascular regions at the depth of the cortical sulci marked by asterisks (be).

\section{Figure 2:}

Illustration of the cascade of events following RHI based on findings of recent studies[40, 42$44,48]$. Following head impact, different forms of tissue pathology, including axonal injury, blood-brain barrier disruption with inflammatory cell extravasation, deafferentation and synapse degeneration caused by distal axonal injury, triggers an acute neuroinflammatory response causing reactive astrogliosis and the initiation of an immune response to repair or limit tissue damage[43]. A combination of factors including the frequency and interval of RHI $[40,76]$ and other unknown genetic and environmental risks collectively impacts on the long-term outcome: neurorestoration and complete recovery or the trigger of a chronic neuroinflammatory state leading to the neurodegenerative cascade and formation of tau pathology. 


\section{Acknowledgements:}

We gratefully acknowledge Kate Strand, Robert Courtney and Karen Davey for their technical contributions to our research projects on CTE. We thank the Reta Lila Weston Institute and the Queen Square Brain Bank for Neurological Disorders, UCL Institute of Neurology for supporting our studies on CTE.

HL and TR are supported by a research grant from CBD Solutions. TR is supported by the NIHR Queen Square Biomedical Research Unit in Dementia based at University College London Hospitals, University College London. The views expressed are those of the authors and not necessarily those of the NHS, the NIHR or the Department of Health.

Authors' contributions:

$\mathrm{HL}$ - drafting and revision of manuscript, preparation of figures and tables

JWN - revision of manuscript

TR - revision of manuscript

\section{Ethical approval:}

Our previous studies on chronic traumatic encephalopathy were conducted at the Queen Square Brain Bank for Neurological Studies (QSBB), UCL Institute of Neurology, under the ethics approval granted by the London Ethics Committee (REC Reference: 02/N093).

\section{Conflict of Interest:}

The authors declare that they have no conflict of interest. 


\section{References:}

1 Martland H. Punch drunk. J Am Med Assoc 1928; 91: 1103-7

2 Millspaugh JA. Dementia pugilistica. US Navy Med Bull 1937: 297-303

3 Critchley M. Punch-drunk syndromes: The chronic traumatic encephalopathy of boxers. Paris: Hommage a Clovis Vincent. 1949

4 Corsellis JA, Bruton CJ, Freeman-Browne D. The aftermath of boxing. Psychological medicine $1973 ; 3: 270-303$

5 McKee AC, Daneshvar DH, Alvarez VE, Stein TD. The neuropathology of sport. Acta Neuropathol 2014; 127: 29-51

6 Goldstein LE, Fisher AM, Tagge CA, Zhang XL, Velisek L, Sullivan JA, Upreti C, Kracht JM, Ericsson M, Wojnarowicz MW, Goletiani CJ, Maglakelidze GM, Casey N, Moncaster JA, Minaeva O, Moir RD, Nowinski CJ, Stern RA, Cantu RC, Geiling J, Blusztajn JK, Wolozin BL, Ikezu T, Stein TD, Budson AE, Kowall NW, Chargin D, Sharon A, Saman S, Hall GF, Moss WC, Cleveland RO, Tanzi RE, Stanton PK, McKee AC. Chronic traumatic encephalopathy in blast-exposed military veterans and a blast neurotrauma mouse model. Sci Transl Med 2012; 4: 134ra60

7 Roberts GW, Whitwell HL, Acland PR, Bruton CJ. Dementia in a punch-drunk wife. Lancet 1990; 335: 918-9

8 Geddes JF, Vowles GH, Nicoll JA, Revesz T. Neuronal cytoskeletal changes are an early consequence of repetitive head injury. Acta neuropathologica 1999; 98: 171-8

9 Hof PR, Knabe R, Bovier P, Bouras C. Neuropathological observations in a case of autism presenting with self-injury behavior. Acta Neuropathol 1991; 82: 321-6

10 Williams DJ, Tannenberg AE. Dementia pugilistica in an alcoholic achondroplastic dwarf. Pathology 1996; 28: 102-4

11 Hof PR, Bouras C, Buee L, Delacourte A, Perl DP, Morrison JH. Differential distribution of neurofibrillary tangles in the cerebral cortex of dementia pugilistica and Alzheimer's disease cases. Acta neuropathologica 1992; 85: 23-30

12 Lampert PW, Hardman JM. Morphological changes in brains of boxers. JAMA 1984; 251: $2676-9$

13 Tokuda T, Ikeda S, Yanagisawa N, Ihara Y, Glenner GG. Re-examination of exboxers' brains using immunohistochemistry with antibodies to amyloid beta-protein and tau protein. Acta neuropathologica 1991; 82: 280-5 
14 Roberts GW, Allsop D, Bruton C. The occult aftermath of boxing. J Neurol Neurosurg Psychiatry 1990; 53: 373-8

15 Mackenzie IR, Neumann M, Baborie A, Sampathu DM, Du Plessis D, Jaros E, Perry RH, Trojanowski JQ, Mann DM, Lee VM. A harmonized classification system for FTLDTDP pathology. Acta Neuropathol 2011; 122: 111-3

16 Neumann M, Sampathu DM, Kwong LK, Truax AC, Micsenyi MC, Chou TT, Bruce J, Schuck T, Grossman M, Clark CM, McCluskey LF, Miller BL, Masliah E, Mackenzie IR, Feldman H, Feiden W, Kretzschmar HA, Trojanowski JQ, Lee VM. Ubiquitinated TDP-43 in frontotemporal lobar degeneration and amyotrophic lateral sclerosis. Science 2006; 314: 1303

17 King A, Sweeney F, Bodi I, Troakes C, Maekawa S, Al-Sarraj S. Abnormal TDP-43 expression is identified in the neocortex in cases of dementia pugilistica, but is mainly confined to the limbic system when identified in high and moderate stages of Alzheimer's disease. Neuropathology : official journal of the Japanese Society of Neuropathology 2010; 30: $408-19$

18 Schmidt ML, Zhukareva V, Newell KL, Lee VM, Trojanowski JQ. Tau isoform profile and phosphorylation state in dementia pugilistica recapitulate Alzheimer's disease. Acta Neuropathol 2001; 101: 518-24

19 McKee AC, Cairns NJ, Dickson DW, Folkerth RD, Keene CD, Litvan I, Perl DP, Stein TD, Vonsattel JP, Stewart W, Tripodis Y, Crary JF, Bieniek KF, Dams-O'Connor K, Alvarez VE, Gordon WA. The first NINDS/NIBIB consensus meeting to define neuropathological criteria for the diagnosis of chronic traumatic encephalopathy. Acta Neuropathol 2016; 131: 75-86

20 Tang-Schomer MD, Johnson VE, Baas PW, Stewart W, Smith DH. Partial interruption of axonal transport due to microtubule breakage accounts for the formation of periodic varicosities after traumatic axonal injury. Exp Neurol 2012; 233: 364-72

21 Smith C, Graham DI, Murray LS, Nicoll JA. Tau immunohistochemistry in acute brain injury. Neuropathol Appl Neurobiol 2003; 29: 496-502

22 Johnson VE, Stewart W, Smith DH. Widespread tau and amyloid-beta pathology many years after a single traumatic brain injury in humans. Brain Pathol 2012; 22: 142-9 23 McKee AC, Stein TD, Nowinski CJ, Stern RA, Daneshvar DH, Alvarez VE, Lee HS, Hall G, Wojtowicz SM, Baugh CM, Riley DO, Kubilus CA, Cormier KA, Jacobs MA, Martin BR, Abraham CR, Ikezu T, Reichard RR, Wolozin BL, Budson AE, Goldstein LE, 
Kowall NW, Cantu RC. The spectrum of disease in chronic traumatic encephalopathy. Brain : a journal of neurology 2013; 136: 43-64

24 Kanaan NM, Cox K, Alvarez VE, Stein TD, Poncil S, McKee AC. Characterization of Early Pathological Tau Conformations and Phosphorylation in Chronic Traumatic Encephalopathy. J Neuropathol Exp Neurol 2016; 75: 19-34

25 Stein TD, Montenigro PH, Alvarez VE, Xia W, Crary JF, Tripodis Y, Daneshvar DH, Mez J, Solomon T, Meng G, Kubilus CA, Cormier KA, Meng S, Babcock K, Kiernan P, Murphy L, Nowinski CJ, Martin B, Dixon D, Stern RA, Cantu RC, Kowall NW, McKee AC. Beta-amyloid deposition in chronic traumatic encephalopathy. Acta Neuropathol 2015; 130: $21-34$

26 Li Y, Li Y, Li X, Zhang S, Zhao J, Zhu X, Tian G. Head Injury as a Risk Factor for Dementia and Alzheimer's Disease: A Systematic Review and Meta-Analysis of 32 Observational Studies. PLoS One 2017; 12: e0169650

27 Fleminger S, Oliver DL, Lovestone S, Rabe-Hesketh S, Giora A. Head injury as a risk factor for Alzheimer's disease: the evidence 10 years on; a partial replication. J Neurol Neurosurg Psychiatry 2003; 74: 857-62

28 Hay J, Johnson VE, Smith DH, Stewart W. Chronic Traumatic Encephalopathy: The Neuropathological Legacy of Traumatic Brain Injury. Annu Rev Pathol 2016; 11: 21-45 29 Gentleman SM, Nash MJ, Sweeting CJ, Graham DI, Roberts GW. Beta-amyloid precursor protein (beta APP) as a marker for axonal injury after head injury. Neurosci Lett 1993; 160: 139-44

30 Sherriff FE, Bridges LR, Sivaloganathan S. Early detection of axonal injury after human head trauma using immunocytochemistry for beta-amyloid precursor protein. Acta Neuropathol 1994; 87: 55-62

31 Chen XH, Siman R, Iwata A, Meaney DF, Trojanowski JQ, Smith DH. Long-term accumulation of amyloid-beta, beta-secretase, presenilin-1, and caspase- 3 in damaged axons following brain trauma. Am J Pathol 2004; 165: 357-71

32 Roberts GW, Gentleman SM, Lynch A, Graham DI. beta A4 amyloid protein deposition in brain after head trauma. Lancet 1991; 338: 1422-3

33 Roberts GW, Gentleman SM, Lynch A, Murray L, Landon M, Graham DI. Beta amyloid protein deposition in the brain after severe head injury: implications for the pathogenesis of Alzheimer's disease. J Neurol Neurosurg Psychiatry 1994; 57: 419-25 
34 Ikonomovic MD, Uryu K, Abrahamson EE, Ciallella JR, Trojanowski JQ, Lee VM, Clark RS, Marion DW, Wisniewski SR, DeKosky ST. Alzheimer's pathology in human temporal cortex surgically excised after severe brain injury. Exp Neurol 2004; 190: 192-203 35 Chen XH, Johnson VE, Uryu K, Trojanowski JQ, Smith DH. A lack of amyloid beta plaques despite persistent accumulation of amyloid beta in axons of long-term survivors of traumatic brain injury. Brain Pathol 2009; 19: 214-23

36 Johnson VE, Stewart W, Smith DH. Traumatic brain injury and amyloid-beta pathology: a link to Alzheimer's disease? Nat Rev Neurosci 2010; 11: 361-70

37 Kovacs GG, Ferrer I, Grinberg LT, Alafuzoff I, Attems J, Budka H, Cairns NJ, Crary JF, Duyckaerts C, Ghetti B, Halliday GM, Ironside JW, Love S, Mackenzie IR, Munoz DG, Murray ME, Nelson PT, Takahashi H, Trojanowski JQ, Ansorge O, Arzberger T, Baborie A, Beach TG, Bieniek KF, Bigio EH, Bodi I, Dugger BN, Feany M, Gelpi E, Gentleman SM, Giaccone G, Hatanpaa KJ, Heale R, Hof PR, Hofer M, Hortobagyi T, Jellinger K, Jicha GA, Ince P, Kofler J, Kovari E, Kril JJ, Mann DM, Matej R, McKee AC, McLean C, Milenkovic I, Montine TJ, Murayama S, Lee EB, Rahimi J, Rodriguez RD, Rozemuller A, Schneider JA, Schultz C, Seeley W, Seilhean D, Smith C, Tagliavini F, Takao M, Thal DR, Toledo JB, Tolnay M, Troncoso JC, Vinters HV, Weis S, Wharton SB, White CL, 3rd, Wisniewski T, Woulfe JM, Yamada M, Dickson DW. Aging-related tau astrogliopathy (ARTAG): harmonized evaluation strategy. Acta Neuropathol 2016; 131: 87-102

38 Wharton SB, Minett T, Drew D, Forster G, Matthews F, Brayne C, Ince PG, Function MRCC, Ageing Neuropathology Study G. Epidemiological pathology of Tau in the ageing brain: application of staging for neuropil threads (BrainNet Europe protocol) to the MRC cognitive function and ageing brain study. Acta Neuropathol Commun 2016; 4: 11

39 Liu AK, Goldfinger MH, Questari HE, Pearce RK, Gentleman SM. ARTAG in the basal forebrain: widening the constellation of astrocytic tau pathology. Acta Neuropathol Commun 2016; 4: 59

40 Cherry JD, Tripodis Y, Alvarez VE, Huber B, Kiernan PT, Daneshvar DH, Mez J, Montenigro PH, Solomon TM, Alosco ML, Stern RA, McKee AC, Stein TD. Microglial neuroinflammation contributes to tau accumulation in chronic traumatic encephalopathy. Acta Neuropathol Commun 2016; 4: 112

41 Ling H, Hardy J, Zetterberg H. Neurological consequences of traumatic brain injuries in sports. Mol Cell Neurosci 2015; 66: 114-22

42 Loane DJ, Kumar A. Microglia in the TBI brain: The good, the bad, and the dysregulated. Exp Neurol 2016; 275 Pt 3: 316-27 
43 Burda JE, Bernstein AM, Sofroniew MV. Astrocyte roles in traumatic brain injury. Exp Neurol 2016; 275 Pt 3: 305-15

44 Smith C, Gentleman SM, Leclercq PD, Murray LS, Griffin WS, Graham DI, Nicoll JA. The neuroinflammatory response in humans after traumatic brain injury. Neuropathol Appl Neurobiol 2013; 39: 654-66

45 Koerte IK, Lin AP, Muehlmann M, Merugumala S, Liao H, Starr T, Kaufmann D, Mayinger M, Steffinger D, Fisch B, Karch S, Heinen F, Ertl-Wagner B, Reiser M, Stern RA, Zafonte R, Shenton ME. Altered Neurochemistry in Former Professional Soccer Players without a History of Concussion. J Neurotrauma 2015; 32: 1287-93

46 Webster SJ, Van Eldik LJ, Watterson DM, Bachstetter AD. Closed head injury in an age-related Alzheimer mouse model leads to an altered neuroinflammatory response and persistent cognitive impairment. J Neurosci 2015; 35: 6554-69

47 Petraglia AL, Plog BA, Dayawansa S, Dashnaw ML, Czerniecka K, Walker CT, Chen M, Hyrien O, Iliff JJ, Deane R, Huang JH, Nedergaard M. The pathophysiology underlying repetitive mild traumatic brain injury in a novel mouse model of chronic traumatic encephalopathy. Surg Neurol Int 2014; 5: 184

48 Briggs DI, Angoa-Perez M, Kuhn DM. Prolonged Repetitive Head Trauma Induces a Singular Chronic Traumatic Encephalopathy-Like Pathology in White Matter Despite Transient Behavioral Abnormalities. Am J Pathol 2016; 186: 2869-86

49 Zetterberg H, Blennow K. Fluid biomarkers for mild traumatic brain injury and related conditions. Nat Rev Neurol 2016; 12: 563-74

50 McKee AC, Gavett BE, Stern RA, Nowinski CJ, Cantu RC, Kowall NW, Perl DP, Hedley-Whyte ET, Price B, Sullivan C, Morin P, Lee HS, Kubilus CA, Daneshvar DH, Wulff $\mathrm{M}$, Budson AE. TDP-43 proteinopathy and motor neuron disease in chronic traumatic encephalopathy. Journal of neuropathology and experimental neurology 2010; 69: 918-29 51 Ling H, Holton JL, Shaw K, Davey K, Lashley T, Revesz T. Histological evidence of chronic traumatic encephalopathy in a large series of neurodegenerative diseases. Acta Neuropathol 2015; 130: 891-3

52 Ling H, Kara E, Revesz T, Lees AJ, Plant GT, Martino D, Houlden H, Hardy J, Holton JL. Concomitant progressive supranuclear palsy and chronic traumatic encephalopathy in a boxer. Acta neuropathologica communications 2014; 2: 24 53 Chio A, Benzi G, Dossena M, Mutani R, Mora G. Severely increased risk of amyotrophic lateral sclerosis among Italian professional football players. Brain 2005; 128: $472-6$ 
54 Chio A, Calvo A, Dossena M, Ghiglione P, Mutani R, Mora G. ALS in Italian professional soccer players: the risk is still present and could be soccer-specific. Amyotroph Lateral Scler 2009; 10: 205-9

55 Schmidt S, Kwee LC, Allen KD, Oddone EZ. Association of ALS with head injury, cigarette smoking and APOE genotypes. Journal of the neurological sciences 2010; 291: 22-9 56 Montenigro PH, Baugh CM, Daneshvar DH, Mez J, Budson AE, Au R, Katz DI, Cantu RC, Stern RA. Clinical subtypes of chronic traumatic encephalopathy: literature reveiw and proposed research diagnostic criteria for traumatic encephalopathy syndrome. Alzheimer's research and therapy 2014: 68

57 Mez J, Solomon TM, Daneshvar DH, Murphy L, Kiernan PT, Montenigro PH, Kriegel J, Abdolmohammadi B, Fry B, Babcock KJ, Adams JW, Bourlas AP, Papadopoulos Z, McHale L, Ardaugh BM, Martin BR, Dixon D, Nowinski CJ, Chaisson C, Alvarez VE, Tripodis Y, Stein TD, Goldstein LE, Katz DI, Kowall NW, Cantu RC, Stern RA, McKee AC. Assessing clinicopathological correlation in chronic traumatic encephalopathy: rationale and methods for the UNITE study. Alzheimers Res Ther 2015; 7: 62

58 Roberts AH. Brain damage in boxers. London: Pitman Medical and Scientific Publishing Co Ltd. 1969

59 Jordan BD. The clinical spectrum of sport-related traumatic brain injury. Nat Rev Neurol 2013; 9: 222-30

60 Victoroff J. Traumatic encephalopathy: review and provisional research diagnostic criteria. Neurorehabilitation 2013; 32: 211-24

61 Stern RA, Daneshvar DH, Baugh CM, Seichepine DR, Montenigro PH, Riley DO, Fritts NG, Stamm JM, Robbins CA, McHale L, Simkin I, Stein TD, Alvarez VE, Goldstein LE, Budson AE, Kowall NW, Nowinski CJ, Cantu RC, McKee AC. Clinical presentation of chronic traumatic encephalopathy. Neurology 2013; 81: 1122-9

62 Stein TD, Alvarez VE, McKee AC. Concussion in Chronic Traumatic Encephalopathy. Curr Pain Headache Rep 2015; 19: 47

63 Ling H, Morris HR, Neal JW, Lees AJ, Hardy J, Holton JL, Revesz T, Williams DD. Mixed pathologies including chronic traumatic encephalopathy account for dementia in retired association football (soccer) players. Acta Neuropathol 2017; 133: 337-52

64 Bieniek KF, Ross OA, Cormier KA, Walton RL, Soto-Ortolaza A, Johnston AE, DeSaro P, Boylan KB, Graff-Radford NR, Wszolek ZK, Rademakers R, Boeve BF, McKee AC, Dickson DW. Chronic traumatic encephalopathy pathology in a neurodegenerative disorders brain bank. Acta Neuropathol 2015; 130: 877-89 
65 Plassman BL, Havlik RJ, Steffens DC, Helms MJ, Newman TN, Drosdick D, Phillips C, Gau BA, Welsh-Bohmer KA, Burke JR, Guralnik JM, Breitner JC. Documented head injury in early adulthood and risk of Alzheimer's disease and other dementias. Neurology 2000; 55: 1158-66

66 Stamm JM, Bourlas AP, Baugh CM, Fritts NG, Daneshvar DH, Martin BM, McClean MD, Tripodis Y, Stern RA. Age of first exposure to football and later-life cognitive impairment in former NFL players. Neurology 2015; 84: 1114-20

67 Stamm JM, Koerte IK, Muehlmann M, Pasternak O, Bourlas AP, Baugh CM, Giwerc MY, Zhu A, Coleman MJ, Bouix S, Fritts NG, Martin BM, Chaisson C, McClean MD, Lin AP, Cantu RC, Tripodis Y, Stern RA, Shenton ME. Age at First Exposure to Football Is Associated with Altered Corpus Callosum White Matter Microstructure in Former Professional Football Players. J Neurotrauma 2015; 32: 1768-76

68 Gardner RC, Burke JF, Nettiksimmons J, Kaup A, Barnes DE, Yaffe K. Dementia risk after traumatic brain injury vs nonbrain trauma: the role of age and severity. JAMA Neurol 2014; 71: 1490-7

69 Alosco ML, Mez J, Kowall NW, Stein TD, Goldstein LE, Cantu RC, Katz DI, Solomon TM, Kiernan PT, Murphy L, Abdolmohammadi B, Daneshvar D, Montenigro PH, Nowinski CJ, Stern RA, McKee AC. Cognitive Reserve as a Modifier of Clinical Expression in Chronic Traumatic Encephalopathy: A Preliminary Examination. J Neuropsychiatry Clin Neurosci 2017; 29: 6-12

70 McKee AC, Alosco ML, Huber BR. Repetitive Head Impacts and Chronic Traumatic Encephalopathy. Neurosurg Clin N Am 2016; 27: 529-35

71 Ojo JO, Mouzon BC, Crawford F. Repetitive head trauma, chronic traumatic encephalopathy and tau: Challenges in translating from mice to men. Exp Neurol 2016; 275 Pt 3: 389-404

72 Goedert M, Jakes R. Expression of separate isoforms of human tau protein: correlation with the tau pattern in brain and effects on tubulin polymerization. EMBO J 1990; 9: 4225-30

73 Ghajari M, Hellyer PJ, Sharp DJ. Computational modelling of traumatic brain injury predicts the location of chronic traumatic encephalopathy pathology. Brain 2017; 140: 333-43 74 Lipton ML, Kim N, Zimmerman ME, Kim M, Stewart WF, Branch CA, Lipton RB. Soccer heading is associated with white matter microstructural and cognitive abnormalities. Radiology 2013; 268: 850-7 
75 Small GW, Kepe V, Siddarth P, Ercoli LM, Merrill DA, Donoghue N, Bookheimer SY, Martinez J, Omalu B, Bailes J, Barrio JR. PET scanning of brain tau in retired national football league players: preliminary findings. Am J Geriatr Psychiatry 2013; 21: 138-44 76 Prins ML, Alexander D, Giza CC, Hovda DA. Repeated mild traumatic brain injury: mechanisms of cerebral vulnerability. J Neurotrauma 2013; 30: 30-8 